\title{
SHIFTING TO TELEMEDICINE PRACTICE DURING COVID-19 LOCK DOWN DAYS: IMPACT ON \\ CHRONIC DISEASE PATIENTS.
}

\begin{abstract}
Aby Paul', Joel Joby Joseph'1., Sanjo Saijan'1., Jude James ${ }^{1}$., Basil John ${ }^{1}$., Edwin Antony \& Jobin Kunjumon
Vilapurathu ${ }^{2}$
\end{abstract}

1.Pharm D Intern, Nirmala College of Pharmacy, Muvattupuzha, Ernakulam, Kerala, India.

2.M Pharm, Associate professor, Department of Pharmacy Practice, Nirmala College of Pharmacy, Muvattupuzha, Ernakulam, Kerala, India.

Email:26abypaul@gmail.com

ABSTRACT

The long lockdown and persisting fear of COVID-19 vulnerabilities of chronic disease patients had severely affected their normal treatment and physician visit cycles. This situation demanded an up rise and practice of the concept of telemedicine. The objective was to analyse the impact of telemedicine among chronic disease patients using a self-reporting numerical rating scale. A cross sectional comparative survey was designed to assess the impact of telemedicine during lock down days among the chronic disease patients by using a patient self-reported numerical rating scale. An anonymous online questionnaire was used to obtain the patient responses. A snowball sampling strategy was adopted to recruit patients into the study. Questionnaire was disseminated through social medias and the obtained responses were analysed. A total of 299 respondents willingly took up and completed the survey questionnaire. Among the 299 patients who participated in the study, $43.84 \%$ had more than one chronic disease, of these 142(37.17\%) patients had autoimmune rheumatic diseases. All patient reported outcomes were better among patients who utilized the telemedicine service than patients who did not had access to the same. The patient reported outcomes related to the overall well-being of the patients in the telemedicine group were 6.515 \pm 2.472 . The patients who had no access to the telemedicine services reported to have overall wellbeing score of 7.166 \pm 2.548 .Telemedicine is one of the best available to promote health care and the Practice of telemedicine was also associated with better patient reported outcomes and quality of life.

Key words: Telemedicine, COVID-19, Chronic disease. 


\section{BACKGROUND}

World health organisation (WHO) declared the novel corona virus disease (COVID-19) as a pandemic on the $11^{\text {th }}$ of March 2020 1. India had its index case reported on the 30th of January in the state of Kerala 2. India was one among the countries in the world to declare the longest lock down across the nation in order to resist the spread of COVID-19. Till date India completed four phases of nationwide lockdown of which phase 1 being initiated on March $25^{\text {th }}, 2020$ 3. It was imperative to control the total patient numbers reaching the hospitals. The limited transportation facilities due to lockdown also reduced the patient access to their hospitals. The long lockdown and persisting fear of COVID-19 vulnerabilities of chronic disease patients had severely affected their normal treatment and physician visit cycles. These conditions had led the entire medical fraternity to explore the opportunities of telemedicine for providing uninterrupted medical care to chronic disease patients. There are reports that many of the chronic disease care units have initiated the usage of telemedicine using social media platforms 4. Hence it was important to analyse and confirm the positive aspects of switching to telemedicine. So we analysed the impact of telemedicine among chronic disease patients using a self-reporting numerical rating scale.

\section{OBJECTIVE:}

The objective was to analyse the impact of telemedicine among chronic disease patients using a self-reporting numerical rating scale.

\section{METHODOLOGY}

Settings and participants
We adopted a cross sectional comparative survey design to assess the impact of telemedicine during lock down days among the chronic disease patients by using a patient self-reported numerical rating scale. We used an anonymous online questionnaire to obtain the patient responses. A snowball sampling strategy was adopted to recruit patients into the study. The target population were the chronic disease patients living in the state of Kerala. The online survey was first disseminated among the students of Nirmala college of Pharmacy, Muvattupuzha and to the patients of a rheumatology center in the area via social Medias. As the Indian Government strictly wanted their citizens to minimize the social contact and to remain in their homes, potential respondents were electronically invited to take up the survey. The questionnaire was prepared in English using Google forms. Language assistance and queries of the participants were attended and clarified on phone via the telephone number provided along with the request message attached with the Google form link circulated in different social Medias. All respondents attended the electronic informed consent.

\section{Study Development}

The survey questionnaire consisted of 11 questions. Socio-demographic factors obtained included age (1), gender(2), educational background(3), chronic disease(4), The sector of hospital they approach (Government/Private).(5). The respondents were asked on their included the accessibility to telemedicine (6).The health conditions and health concerns were evaluated with a set of 
dichotomous questions and numerical rating scales (NRS). The numerical rating scales ranged from 0 to 10 . In this 0 denoted 'not worried or satisfactory' and 10 on scale denoted 'worried or not satisfactory'. NRS questions were evaluated to rate their concerns on reduced access to health care during the lock down days(7), considerations about the safety of the medicines they were consuming during the lock down period (8) and their concerns about acquiring COVID-19 infections because of their chronic disease state(9) and their overall wellbeing during this lockdown. (10).

\section{Patient reported outcomes}

The patient reported outcomes were mainly assessed using the NRS scales. It covered the patient concerns regarding the limited access to health care services during the lockdown, safety of medicines they are consuming, acquiring covid-19 infection because of their chronic disease and their overall wellbeing during this lockdowns. All these patient reported outcomes were compared between the 2 study groups namely patients who adopted telemedicine and patients who did not.

\section{Statistical Analysis}

Descriptive statistics were calculated for age and NRS questions. Chi-square test was used to analyse the association between the categorical variables. We used t-test to analyse the age and for NRS questions in both disease groups. All test were two- tailed, with level of significance, $p<0.05$. Statistical analysis was performed using SPSS statistics 21.0 (IBM SPSS Statistics, New York, United States).

\section{RESULTS}

A total of 299 respondents willingly took up and completed the survey questionnaire. Among them about 169(56.52\%) had access to telemedicine, whereas $130(43.47 \%)$ of them didn't had the opportunity to utilize the telemedicine service. All study relevant parameters like distribution of age, gender, educational status, NRS based patient reported outcomes regarding their health and health concerns during the COVID-19 lockdown were analysed.

Among the 299 patients who participated in the study, $43.84 \%$ had more than one chronic disease, of these $142(37.17 \%)$ patients had autoimmune rheumatic diseases, 114(29.84\%) had life style and endocrine disorders like diabetes, hypertension, dyslipidaemia, thyroid disorders, 58(15.18\%) patients had cardiac disorders, 34(8.90\%) patients had respiratory diseases , 24(6.28\%) patients had gastrointestinal disorders and 10(2.61\%) had malignancy. 
Table 1: Comparisons of socio-demographic factors and NRS questions

\begin{tabular}{|c|c|c|c|c|}
\hline $\begin{array}{c}\text { Socio- } \\
\text { demographic } \\
\text { characteristics }\end{array}$ & $\begin{array}{l}\text { Options for } \\
\text { respondents }\end{array}$ & $\begin{array}{l}\text { Patients who } \\
\text { accessed } \\
\text { telemedicine } \\
\quad(n=169)\end{array}$ & $\begin{array}{l}\text { Patients who didn't } \\
\text { accessed } \\
\text { telemedicine }(\mathrm{n}=130)\end{array}$ & $\begin{array}{l}\mathrm{P} \text { value } \\
\text { (2-tailed } \\
\text { test })\end{array}$ \\
\hline \multicolumn{2}{|c|}{ Age(Mean \pm SD.Dev) } & $49.893 \pm 14.544$ & $58.031 \pm 16.996$ & 0.000 \\
\hline \multirow[t]{2}{*}{ Gender } & Female $(\mathrm{n}=193)$ & $111(65.68 \%)$ & $82(63.07 \%)$ & \multirow[b]{2}{*}{0.641} \\
\hline & $\operatorname{Male}(n=106)$ & $58(34.31 \%)$ & $48(36.92 \%)$ & \\
\hline \multirow{4}{*}{$\begin{array}{l}\text { Educational } \\
\text { Background }\end{array}$} & High School $(n=118)$ & 41 & 75 & \multirow{4}{*}{0.000} \\
\hline & Undergraduate $(\mathrm{n}=111)$ & 73 & 38 & \\
\hline & Post graduate $(\mathrm{n}=64)$ & 50 & 14 & \\
\hline & $\begin{array}{c}\text { Doctor of } \\
\text { Philosophy }(\mathrm{n}=8)\end{array}$ & 5 & 3 & \\
\hline
\end{tabular}

Numerical Rating Scale (0-not worried or satisfactory, 10-worried or not satisfactory)

\begin{tabular}{|c|c|c|c|}
\hline $\begin{array}{c}\text { Reduced access to health care services } \\
\text { (Mean } \pm \text { SD.Dev) }\end{array}$ & $4.414 \pm 3.241$ & $4.577 \pm 3.064$ & 0.650 \\
\hline $\begin{array}{c}\text { Concerns regarding the medicines they } \\
\text { use in COVID-19 season (Mean } \pm\end{array}$ & $3.521 \pm 2.984$ & $4.192 \pm 2.748$ & 0.047 \\
\hline SD.Dev) & & $2.562 \pm 1.311$ & 0.199 \\
\hline $\begin{array}{c}\text { Concerns regarding acquiring COVID- } \\
19 \text { (Mean } \pm \text { SD.Dev) }\end{array}$ & $2.351 \pm 1.351$ & & \\
\hline $\begin{array}{c}\text { Overall wellbeing during lockdown } \\
\text { (Mean } \pm \text { SD.Dev) }\end{array}$ & $6.515 \pm 2.472$ & $7.166 \pm 2.548$ & 0.027 \\
\hline
\end{tabular}

\section{SD.Dev=standard deviation}

The mean age of the patients who utilized the telemedicine services were $49.893 \pm 14.544$ and the mean age of the patients who did not attended the telemedicine services were 58.031 \pm 16.996 ( $\mathrm{p}<0.05$ ), which was higher than the mean age of the telemedicine utilised study group. A female dominance was observed in both chronic disease groups (group 1 vs group 2). Both study groups had an equal distribution of female with $111(65.68 \%)$ in the telemedicine group and $82(63.07 \%)$ in non-telemedicine study group ( $p>0.05)$. The educational background of patients were assessed and it was found that patients with higher educational status were in the telemedicine group $(\mathrm{p}<0.05)$. The patient 
reported outcomes were assessed using NRS scales. All patient reported outcomes were better among patients who utilized the telemedicine service than patients who did not had access to the same. The concerns regarding the medicines they use for the management of their chronic disease during the COVID-19 struck days were higher in the patients who didn't had access to the telemedicine facility (4.192 \pm 2.748 vs $3.521 \pm 2.984 ; p<0.05)$. The patient reported outcomes related to the overall well-being of the patients in the telemedicine group were 6.515 \pm 2.472 . In contrary to this, the patients who had no access to the telemedicine services reported to have overall well being score of 7.166 \pm 2.548 .The overall well being of the patients in the telemedicine group was found to have positive outcomes when compared with the other group $(p<0.05)$.

Discussion

Indian medical association (IMA) had officially formulated and published guidelines for practice of telemedicine in India. These guidelines were notified under the Indian Medical Council (Professional Conduct, Etiquette, and Ethics) Regulations, 2002_5. This accelerated actions of the IMA is attributed to the nationwide lockdown that was declared on March 5th, 2020 to reduce the patient flow into the hospitals and to maintain the continuous medical accessibility for all patients to meet their medical needs. In accordance with these the entire medical fraternity of India switched their consultations into the online telemedicine to serve their patients 6. The private and the government hospitals of Kerala were equiped to treat their patients with online telemedicine under the E-Sanjeevani for non-COVID patient care $\underline{7}$. Thus Kerala was one of the leading states in the nation that extended their health care systems with the use of telemedicine. The positive impact of medical care with telemedicine can be attributed to Kerala's internet penetration which is reported to be the second highest in the nation 8 .But ultimately the impact of telemedicine has to be assessed based on the patient reported outcomes. Hence we conducted a comparative cross sectional survey to record and analyze patient reported outcomes on numerical rating scale among patients who chose to use telemedicine consultations and who did not had access to the same. Of the 299 patients who participated in our study, $169(56.52 \%)$ consulted through telemedicine whereas $130(43.47 \%)$ did not had access for using telemedicine for the treatment of their chronic diseases. The younger age and high educational status of the patients in the telemedicine group supported the hypothesis that respondents with higher e-Health literacy would be younger and more educated $?$. Analysis of the patient reported outcomes clearly showed positive responses from the patients who attended the telemedicine consultations. Concerns about the safety of medicines they use were much less in the telemedicine group. The safety concerns of many treatment agents like ACE inhibitors, Hydroxychloroquine etc used for the treatment of different chronic diseases where stipulated in the Medias, that they bear an additional risk for being infected with COVID-19 and were associated with several life threatening 
adverse effects $10, \underline{11}$. Telemedicine had played an important role in improving the health literacy of the chronic disease patients. Thus telemedicine had improved the confidence of the patients about the safety of their medicines and encouraged them to be completely adherent to their regular medicines. Medication adherence is a key factor associated with anticipated outcomes in chronic diseases. But inadequate health literacy can result in medication nonadherence and poor health outcomes 12.The telemedicine group also reported to have better overall well-being compared to the other study group during the lockdown period. The overall well-being also reflected their better quality of life. Mental and physical stress experienced by chronic disease patients is profound factors that determine their quality of life. 13. The limited physical activity and social involvement during the long lockdown days are inversely related to the physical and mental stress experienced by a patient 14. This had significantly increased the number of suicide in India which claimed over 300 deaths being reported during these lockdown phase. This incidence itself can explain the impact of psychological stress persisting over the Indian population 15 . The fact that increased stress and health related quality of life can have a negative impact on the disease severity addresses the urgent need of medical attention for the chronic disease patients 16,17.Thus the better overall well-being score observed among the telemedicine group proved to be a health intervention that can be adopted in order to identify the uncertainties and to offer medical assistance whenever needed.

Telemedicine can be utilised in an efficient way to tackle the short comings of medical emergencies or pandemic that demands the reduction in patient inflow to the hospitals. The implementation of telemedicine can also be considered as an economically viable health intervention to meet the health demands of chronic disease patients during the lockdown. Many past researches had demonstrated better cost utility and cost effective models for telemedicine in comparison with the standard health care visits 18 . The reduced cost of telemedicine may be due to the reduction in indirect medical cost and better incremental net monetary benefit when compared to the conventional health care visits $\underline{19}$.

Kerala's COVID-19 statistics is one of the best performers in India 20 . The implementation of telemedicine reduced the chronic disease patients inflow to the hospitals and reduced the risk of COVID19 infections among these vulnerable populations $\underline{21}, \underline{22}$. Although more health care workers were infected with COVID19 and hospitals turning out to be the epicentre of COVID-19 transmission in Kerala 23 , the state managed to maintain its COVID-19 cases low and under control with the execution of pre planned health services like telemedicine.

But it should be noted that even in our study $130(43.47 \%)$ patients had no access to telemedicine. We have to explore methods to expand this facility even to the marginalised communities of the state or else we may witness a digitally divided health scenario $\underline{24}$.

Limitation of our study 
No standardised questionnaires or rating scales were used to analyse the anxiety or healthy related quality of life.

Conclusion

Our study concluded that telemedicine is one among the best available alternative to overcome the current COVID-19 conditions which demands controlled or reduced patient inflow to the hospital. Practice of telemedicine was also associated with better patient reported outcomes and quality of life. But before implementations of such health care interventions keen efforts have to be made in order to avoid any chances of evolution of a digitally divided health policy standard.

\section{Conflict of interest}

Conflict of interest statement: The authors have no conflicts of interest.

Data Availability : Data can be made available when contacted with the corresponding author

Reference

1. Organization WH(2020) WHO DirectorGeneral's opening remarks at the media briefing on COVID-19-11 March 2020. Geneva, Switzerland

2. Anon. India's Third Coronavirus Patient Discharged from Hospital. NDTV.com. retrieved from

https://www.ndtv.com/india-news/covid19-cases-indias-third-coronavirus-patientdischarged-from-hospital-2183009.

Accessed June 18, 2020

3. Shivani Phaugat( June 3 , 2020). India Lockdown 5.0: Covid-19 unlock action plan.ETCFO. retrieved from https://cfo.economictimes.indiatimes.co $\mathrm{m} /$ news/india-lockdown-5-0-covid-19unlock-action-plan/76167820 .Accessed June 18, 2020
4. Shenoy, P., Ahmed, S., Paul, A. et al. Switching to teleconsultation for rheumatology in the wake of the COVID19 pandemic: feasibility and patient response in India. Clin Rheumatol (2020). https://doi.org/10.1007/s10067-020-05200b

5. Trisha Jalan March 31, 2020 summary: India's telemedicine guidelines 2020.retrieved from https://www.medianama.com/2020/03/2 23-summary-india-telemedicineguidelines/ .Accessed June 18,2020

6. K Ganapathy,April 18, 2020, COVID-19 enhances reliance on telemdicine. retrieved from https://www.thehindu.com/news/nationa l/tamil-nadu/covid-19-enhances-relianceon-telemedicine/article31378946.ece

Accessed on June 18,2020

7. Kerala govt to use telemedicine service e-Sanjeevani for non-COVID patient care ,June 14,2020 ,retrieved from https://economictimes.indiatimes.com/in dustry/healthcare/biotech/healthcare/ke rala-govt-to-use-telemedicine-service-esanjeevani-for-non-covid-patientcare/articleshow/76370573.cms? from $=m$ dr , Accessed on June 18,2020

8. Varun Krishnan ,November 7, 2019 Data: Where does Kerala's Internet access stand compared to other States? retrieved from https://www.thehindu.com/news/nationa l/where-does-kerala-internet-access-

stand-compared-to-otherstates/article29910398.ece, Accessed on June 18,2020

9. Neter E, Brainin E ,eHealth Literacy: Extending the Digital Divide to the Realm of Health Information, J Med Internet Res 2012;14(1):e19,DOI: 10.2196/imir.1619

10.G.Anathakrishnan, March 20,2020 , Coronavirus | Do anti-hypertensive drugs 
raise the risk for COVID-19 patients? retrieved from https://www.thehindu.com/scitech/health/coronavirus-do-antihypertensive-drugs-raise-the-risk-forcovid-19-patients/article31113082.ece Accessed on June 18,2020

11. Mercuro NJ, Yen CF, Shim DJ, et al. Risk of QT Interval Prolongation Associated With Use of Hydroxychloroquine With or Without Concomitant Azithromycin Among Hospitalized Patients Testing Positive for Coronavirus Disease 2019 (COVID-19) [published online ahead of print, 2020 May 1]. JAMA Cardiol. 2020;e201834.

doi:10.1001/jamacardio.2020.1834

12. Lee YM, YU HY, You MA, Son YJ. Impact of health literacy on medication adherence in older people with chronic diseases. Collegian. 2017; 24(1):11-18. doi:10.1016/j.colegn.2015.08.003

13. Czyżewski Ł, Frelik P, Wyzgał J, Szarpak $Ł$. Evaluation of Quality of Life and Severity of Depression, Anxiety, and Stress in Patients After Kidney Transplantation. Transplant Proc. 2018:50(6):1733-1737. doi:10.1016/j.transproceed.2018.04.026

14. Stults-Kolehmainen MA, Sinha R. The effects of stress on physical activity and exercise. Sports Med. 2014;44(1):81-121. doi:10.1007/s40279-013-0090-5

15. Suicide leading cause for over 300 lockdown deaths in India, says study, May 5,2020, retrieved from https://economictimes.indiatimes.com/n ews/politics-and-nation/suicide-leadingcause-for-over-300-lockdown-deaths-inindia-says-

study/articleshow/75519279.cms

Accessed on June 18,2020

16. Polis S, Fernandez R. Impact of physical and psychological factors on healthrelated quality of life in adult patients with liver cirrhosis: a systematic review protocol. JBI Database System Rev Implement Rep. 2015;13(1):39-51. doi:10.11124/jbisrir-2015-1987

17. Wierenga KL, Lehto RH, Given B. Emotion Regulation in Chronic Disease Populations: An Integrative Review. Res Theory Nurs Pract. 2017;31(3):247-271. doi:10.1891/1541-6577.31.3.247

18. de la Torre-Díez I, López-Coronado M, Vaca C, Aguado JS, de Castro C. Costutility and cost-effectiveness studies of telemedicine, electronic, and mobile health systems in the literature: a systematic review. Telemed J E Health. 2015;21 (2):81-85.

doi:10.1089/tmj.2014.0053

19. de Jong MJ, Boonen A, van der Meulende Jong $A E$, et al. Cost-effectiveness of Telemedicine-directed Specialized vs Standard Care for Patients With Inflammatory Bowel Diseases in a Randomized Trial [published online ahead of print, 2020 Apr 23]. Clin Gastroenterol Hepatol. 2020;S15423565(20)30535-8.

doi:10.1016/j.cgh.2020.04.038

20. Soniya Falerio, April 13,2020, What the world can learn from Kerala about how to fight covid-19, retrieved from https://www.technologyreview.com/2020 104/13/999313/kerala-fight-covid-19-

india-coronavirus/ Accessed on June 18,2020

21.Li B, Yang J, Zhao F, Zhi L, Wang X, Liu L, et al. Prevalence and impact of cardiovascular metabolic diseases on COVID-19 in China. Clin Res Cardiol. 2020. Epub

2020/03/13. doi: 10.1007/s00392-02001626-9. PubMed PMID: 32161990.

22. Deaths rise to 16 , comorbidities main reason, June 9,2020 , retrieved from 
https://www.newindianexpress.com/state s/kerala/2020/jun/09/deaths-rise-to-16comorbidities-main-reason-2153981.html , Accessed on June 18,2020

23. Ayappan R, May 26,2020 , Rising COVID-19 cases among health workers a telltale sign of community transmission? retrieved from https://www.onmanorama.com/news/ke rala/2020/05/25/covid-19-cases-healthworkers-community-transmissioncoronavirus.html Accessed on June $\underline{18,2020}$

24. Connolly KK, Crosby ME. Examining e-Health literacy and the digital divide in an underserved population in Hawai'i.

25. Hawaii J Med Public Health. 2014;73(2):44-48. 